\title{
Editorial
}

\section{Behavioural and Cognitive Psychotherapy and Cambridge University Press}

As I am sure you cannot have failed to notice, the Journal has taken on quite a different look, thanks to Cambridge University Press. In addition, there have been changes in the Editorial Advisory Board. We welcome some new members, and say farewell and thanks to some old friends. Members of the new Editorial Board are going to be very directly involved in advising the editors and assistant editors in matters relevant to particular issues and geographical regions.

As far as the content of the Journal is concerned, there will be a major new addition to the range of articles included. At present, journal sections include Accelerated Publication, Main Section, Clinical Section and Brief Clinical Reports. In the next issue of the Journal we will introduce a new section, Leading Articles. These will be short articles identifying and clarifying issues and trends in the field of cognitive and behavioural therapies. It is anticipated that they will range from the discussion of theoretical issues through to analyses or warnings about trends in the field, ethical issues, comments on new approaches to therapy or its delivery and so on. It is intended that these articles will draw readers' attention to important issues (or issues that the writers believe should be important), and that they will cover topics that would not usually form the subject matter of longer empirical or review articles. Leading articles will usually be specifically invited, but all will be subject to peer review. As ever, I will be happy to receive comments and suggestions from readers of the Journal about this or any other matter.

It just remains for me to thank retiring members of our editorial groups and welcome the new ones, and to look forward to a long and fruitful collaboration between Cambridge University Press and this journal.

Paul Salkovskis 